such feathers show a faint yellow colour by transmitted light, and any pressure which destroys the structure also destroys all colour. The small bodies which scatter the light are in this case said to be exceedingly minute air-canals, which, on being filled with fluid, lose this property. In the case of feathers, as well as of certain animals, such as green frogs and many reptiles, the green is said to be due to the additional effect of a yellow pigment which is superimposed on the blue colour, as in the case of Ornithoptera poseidon, already described. There are also some exceedingly brilliant marine copepods which owe their colours to a prismatic layer of minute rods, said to be small enough to scatter coloured light.

In most beetles the metallic colours are seen to come from the surface, and the slightest scratch on the elytron removes all the colour. In the case, however, of certain emerald-green and blue Cetoniids, the colour appears to come from underneath the surface, which gives the wing-case a curious enamelled appearance. This peculiarity can be instantly recognised, and, moreover, the colour, though matt, is seen to persist, even when the surface layer has been removed with a scalpel. This layer has been called the "Emailschicht," and when sections are cut from it tangentially to the surface, 6 (Fig. 2), they give a bright green colour by reflected light, even when mounted in fluid media. A transverse section, 7 (Fig. 2), was cut from this layer of a beetle called Heterorrhina elegans; it is seen to be made up of very fine rods of chitin, $r_{1}$, about $I \mu$ apart, and arranged at right angles to the surface; $r_{2}$ represents a second layer of rods at a lower depth. The section, 6 (Fig. 2), made through the line $a b$ of section 7 , reveals the cut ends of the rods. Thus the light, on striking the wing-case, is reflected from the tips or ends of a large number of these rods or pillars, and it seems possible that they may scatter the light in the same way as the air-canals do in the case of birds' feathers. It must, however, be pointed out that the above theory demands that the rods, or other bodies which scatter the light, should be appreciably smaller than the wave-length of light; that is to say, not much larger than a complex molecule. It is, however, uncertain whether bodies of the same order of magnitude as light waves (i.e. $0.5^{-1} \cdot 0 \mu$ ) can produce analogous colours. A very remarkable point about these rods of chitin is that under crossed Nicols they appear to be doubly refractive. This suggests that there may be some analogy with doubly refractive striated crystals like the tourmaline.

(To be continued.)

\title{
Physical Anthropology of Ancient and Modern Greeks.
}

\section{By L. H. Dudley Buxton.}

T $N$ classical times a clear distinction was drawn between Greek and Barbarian; Aristotle, indeed, claimed that they differed physically. To a certain extent it may be shown that in detail Aristotle had right on his side, but it can also be shown that Greek differs physically from Greek, so that his general thesis is untenable. It is true that most of our evidence rests on measurements made on modern Greeks, but there are data to prove that the latter possess physical characteristics not differing essentially from those of the former.

Among recent writers it has been generally admitted that at least two races are represented in Greek lands-the "Mediterranean" and the "Alpine." The former are short in stature, dark in colouring, and long-headed, typically represented by the Spaniards; the latter are fairer, and often, but not invariably, have auburn hair and hazel eyes, and vary very much in stature. The Eastern branch of the Alpines are usually known as "Armenoids." They are distinguished by their short, high heads, which are extremely flattened in the occipital region. It has also been suggested that long-headed, blond giants-Nordic-have contributed to the population of Greek lands.

Of the aboriginal population there is little evidence at present. Von Luschan believes that, at any rate in Anatolia, the earliest people were Armenoids, and in the Morea Prof. Myres considers that the Alpine strain is certainly ancient and may even be primitive. Early material is, however, so rare that it is easier, in stating the problem before us, to reverse the time process and to study the ancient people after the modern, about whom we are better informed.

The mean cephalic index in Greek lands to-day varies from 79 in Crete to 84 in the island of Leukas. None of the Greeks are as long-headed as the pure Mediterranean type, such as we find in a comparatively pure form in Corsica or Spain and in a less pure form in Egypt; nor, again, are they as broad-headed as the Lycian gipsies, who certainly represent pure Armenoids. If we group such cephalic indices on the living as are available, we obtain three classes: (I) Under 8r, Cretans, Peloponnesians, Lycians (Greeks and Turks); (2) intermediate, Messenians and Cypriots; (3) more than 84, Leukadians, Albanians, Lycian gipsies. It would appear unlikely that this grouping is of any significance, if we turn from these figures to the variation, conveniently measured by taking the square root of the average square deviation from the mean (standard deviation). The Lycian Greeks and Turks have a very high standard deviation, suggesting considerable mixture, and the standard deviation of the cephalic indices of all the Greeks is sufficient to suggest a greater or less degree of intermixture. The condition of intermixture in Cyprus can be seen in Fig. I-a photograph of a Cypriot woman and her three children. The elder boy might easily have been taken for an almost

NO. 2658 , VOL. IO6] 
pure Armenoid; the younger had many characters usually associated with the Mediterranean people. The inadequacy of grouping by cephalic index alone is confirmed by the very great local differences to be found between groups of villages in Cyprus, to take one example only. The villages on the north coast have a cephalic index of 81.9 , those round the Bay of Salamis, just the other side of the hills, an index of 83.4 . There are similar local differences in Crete.
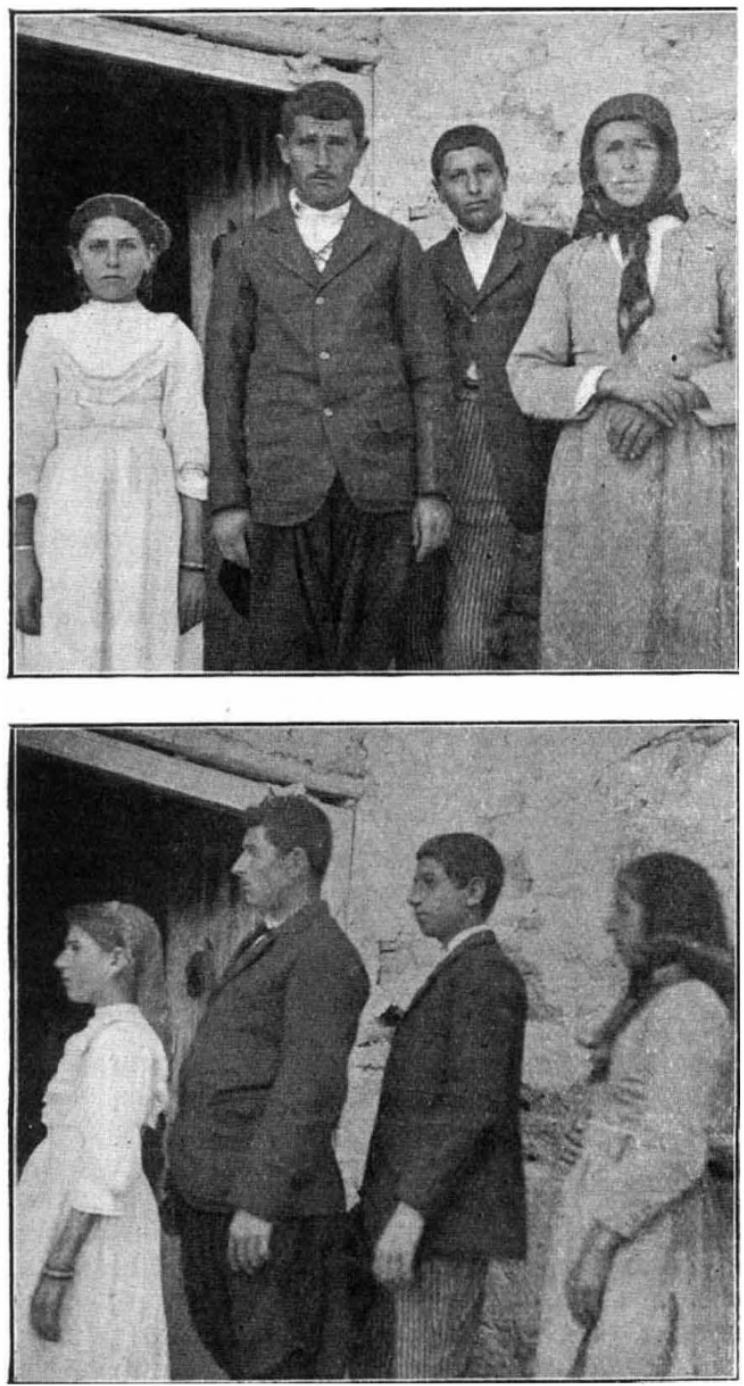

FIG. 1.-A Greek family, showing the two extreme types. The father (not shown in the photograph) had fair hair and blue eyes. The contrasted contours of the backs of the head should be noticed.

If we compare ancient crania with modern heads it would appear that the modern Greeks are slightly more round-headed than the ancient inhabitants of the same places. But this difference is not of any great significance, and there is a greater resemblance between the modern inhabitants of any one place and their predecessors than between the modern inhabitants of two neighbouring areas; in other words, the variation of types No. 2658 , VoL. IO6] at any stage is horizontal, and not vertical, in the strata. First, the cranial indices, then, of the Greeks exhibit great variety, sufficient to suggest ethnic admixture. Secondly, this admixture has not been evenly distributed, and local and distinct sub-races have been formed, the mean of which forms a series of types, one of which is illustrated in Fig. 2-a type which has neither the breadth of head of the Armenoid, nor the length of head of the Mediterranean. So distinct are these subraces that ${ }^{\circ}$ where crania over a long period have been obtained the cephalic index of one modern village more closely resembles that of their Bronze-age predecessors than that of a neighbouring area. Thirdly, there is archæological material which suggests that the mixture of race is early, possibly Neolithic in Leukas, certainly Bronze-age (or before) in Cyprus and Crete.

So few complete ancient skeletons have been collected that we cannot estimate the stature of the ancient Greeks. Among the modern, we find that

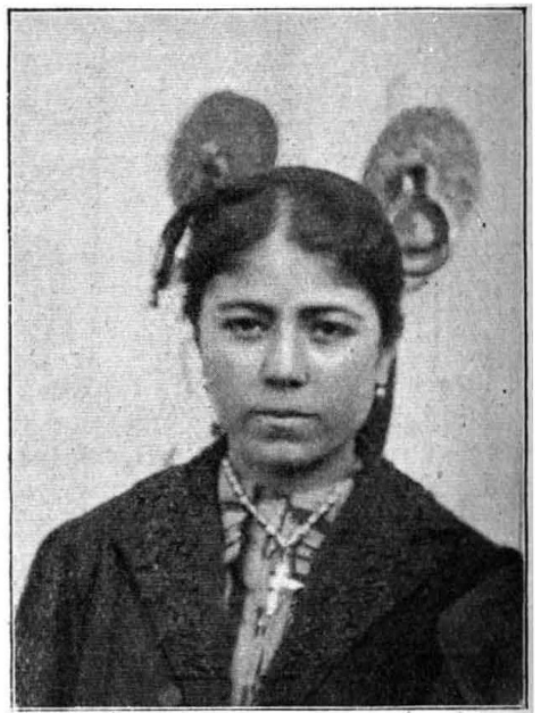

FIG. 2.-An intermediate type, with hazel eyes and brown hair.

the Cypriots and Cretans are the tallest, averaging about $5 \mathrm{ft}$. $6 \frac{1}{2}$ in., and the Leukadians and Peloponnesians the shortest, being about an inch shorter. So few measurements are, however, at present available that the stature must remain uncertain.

Data for hair and eye colour are rather scanty. The number of blue-eyed individuals is not, however, so few as might be expected. In Cyprus they form about ro per cent. of the population, and most authorities are in agreement that blue eyes are not rare in Greek lands. 'It is this occurrence of light eyes that has made some writers postulate the presence of Nordics among the Greeks. Speaking from personal experience, the author was struck by the continual association of blue eyes with a very Armenoid type of skull in Cyprus and elsewhere-the taller boy in Fig. I is a good instance of this type-and though, historically, no doubt Nordics have filtered into the 
Eastern Mediterranean at various times, the evidence of blue eyes is certainly insufficient to establish their presence as a recognisable element in the population.

The distribution of other characters, such as the form of the nose and of the orbits, cannot at present be plotted, as the evidence is scanty. Such measurements as have been made on the face suggest that, among the Greeks at any rate, broad faces accompany broad heads, and vice versa.

If we sum up the evidence afforded by all the physical characters which have been measured, we find that the Greeks probably represent a very old hybrid, older than the beginnings of the Bronze age. In Cyprus the earliest skulls examined were found associated with red polished and white painted ware, and were clear examples of this hybrid. We cannot at present say whether these early Greeks formed this physical type in the island or before they reached it. Elsewhere, so far as our scanty data go, the same tale seems probable. In each little district there is a mixture; sometimes the population of widely distant spots is similar; sometimes villages close to one another differ. It must be remembered that the geography of Greek lands favours the development of local strains, communication being often very difficult. There does seem to be a physical background to the differences between village and village in classical times, and to the struggles between Athens and Sparta. Most of the inhabitants of the Eastern Mediterranean, however, are also of this hybrid stock, and so Aristotle's dictum seems unjustified. There is no physical background for Hellas as a whole. Our present evidence suggests that the degree of mixture is fairly uniform throughout, though the results of the mixing may be different. Lycia, however, presents a far greater degree of heterogeneity; this heterogeneity did not escape the notice of Herodotus, who says that the Lycians were Cretan immigrants into a country with a previous Minyan population, with a third element from Attica.

There is little reason to doubt the generally accepted statement that the two stocks which have formed this hybrid are Mediterranean and Armenoid. The former is found in a comparatively pure state to the west and south of the Greek world, the latter sporadically in a pure state among the Greeks of Anatolia, and may even occur, though we have no evidence at present, in the Balkan Peninsula itself.

\section{Obituary.}

Alfred E. Fletcher.

$\mathrm{B}^{\mathrm{Y}}$ $\mathrm{Y}$ the death of Alfred E. Fletcher, at the great age of ninety-four, the country has lost a scientific worker who, in his particular sphere, exercised on chemical manufacture a powerful and healthful influence. Born in 1826 , Fletcher completed his school education in Berlin, and was employed for a time on railway surveying. He relinquished his career as an engineer in order to attend the science classes at University College, London (being debarred as a Nonconformist from attending the older universities), where he studied mathematics and chemistry, for which he received the gold medal in $185 \mathrm{I}$. In the following year he was elected a fellow of the Chemical Society, and afterwards began a series of researches on artificial colouring matters, a field of inquiry which had been developed by Perkin's discovery of mauve in 1856 , and greatly stimulated by the work of Hofmann and his pupils at the Royal College of Chemistry. Discouraged by prolonged litigation on the subject of a patent for a new colour process in which he was interested, Fletcher accepted in 1863 the post of assistant to Dr. Angus Smith, the first Chief Alkali Inspector. The origin of this department, which played so large a part in Fletcher's subsequent career, was the numerous complaints from farmers owing to the fumes from alkali and other chemical works. These fumes arose mainly from the discharge of hydrochloric acid in the manufacture of salt-cake. These and other acid vapours destroyed vegetation over large areas.

Under the Alkali Act of 1863 trained chemists were appointed to control this industry. The No. 2658 , VOL. IO6] result of such inspection was soon apparent. The acid, which has since become a staple and profitable product of the process, was absorbed in towers by passing the gases through a descending stream of water. This is not by any means the only example whereby the alkali inspectors have helped the chemical manufacturer to utilise his noxious by-products to his own advantage and to that of the public.

As assistant, Fletcher devised an ingenious aspirator for extracting flue gases for analysis, and also invented an anemometer for determining their rate of flow. In 1884 , on the death of Dr. Smith, he succeeded him as Chief Inspector, and continued in that office until his retirement in 1895 .

Fletcher's activities were not confined to clearing the atmosphere from noxious fumes. $\mathrm{He}$ entered upon a campaign against the smoke nuisance, which he continued for thirty years, embodying his views in a series of articles, addresses, and pamphlets. He was, so far as the writer remembers, a strong advocate of a centralised inspectorate of all factory chimneys on the lines of the Alkali Act, and set an example of domestic heating without smoke by installing a central warm air system in his own house, details of which he published in the Press and technical journals. He also assisted the Scottish Office in the administration of the Rivers Pollution Act.

Fletcher married in ${ }_{18} 88$ Sarah Elizabeth, eldest daughter of Richard Morley, of Leeds, and is survived by his wife, six sons, and three daughters.
J. B. C. 